\title{
'Kimberley Brownlee: Being Sure of each Other. An Essay on Social Rights and Freedoms' Oxford: Oxford University Press, 2020
}

\author{
Enrico Biale ${ }^{1}$ (D)
}

Accepted: 28 May 2021/ Published online: 3 June 2021

(C) The Author(s), under exclusive licence to Springer Nature B.V. 2021

The Covid-19 pandemic and the measures adopted almost everywhere to contain the spread of the virus and reduce its impact on our health and lives significantly limited our social interactions.

Despite the costs of these measures, especially for the most marginalized and vulnerable members of our societies, they had been a necessary price to pay. Yet it is undebatable that these limits on our social interactions were a burden for everyone precisely because, as Kimberly Brownlee clearly shows in Being Sure of Each Other, we are social creatures that need human contact to properly live and function. While sociality is clearly considered fundamental when we are children and deeply depends on other individuals, its importance is underestimated both in the public and academic debates when we become fully autonomous agents.

Brownlee effectively challenges this shared view and develops a threefold argument that we have fundamental social needs throughout our lives. Firstly, her analysis focuses on the empirical evidence from psychology and neuroscience that points to the importance for our development and health of belonging and social connections throughout our lives. Secondly, she claims that since we experience the world in interpersonal terms by making sense of who we are and what we value through our connections with other people, these social connections are clearly relevant for us. Finally, she holds that we have a respect-based duty to recognize the importance of social connections precisely because these connections define our purposes and are part of the deliberative process that constitutes our agency.

Not only does Being Sure of Each Other show that certain social goods are necessary to lead minimally good lives, but it points out that they are a constitutive part of such lives. This view allows Brownlee to justify a human right against social deprivation that entails an enriched and challenging account of moral duties and justice. Being there for others, Brownlee contends, is both a value and a duty. Given the pivotal role of sociality in shaping our values, fostering our abilities to interact with others, and being publicly acknowledged as social cooperators, being there for others is both instrumentally and intrinsically valuable for

Enrico Biale

enrico.biale@uniupo.it

1 University of Piemonte Orientale, Vercelli, Italy 
everyone. This explains why we are victims of social contribution injustice when our opportunities to significantly contribute to the lives of others are curtailed or misrecognized. This state of affairs, Brownlee concludes, prevents us from exercising our humanity and flourishing.

If this perfectionistic approach is at odds with a liberal interpretation of justice, a human right against social deprivation has consequences for our personal freedoms that raises even larger challenges. Brownlee shows that if we acknowledge the importance of social connection and accept her interpretation of justice, we have to rule out the idea that "we have a largely unqualified right to interact or not with strangers as we please" (Brownlee 2020). This perspective does not deny our interest in controlling whether and how to interact with people, but it does indicate that our interest in connecting with others and appropriately responding to their interactional requests have priority, especially if these requests are raised by vulnerable and excluded individuals. If everyone rejected such individuals' claims, the latter's right to be free of social deprivation would not be protected. Though this view significantly revises the scope and content of our personal freedoms, it represents a powerful tool to challenge the institutions and practices that systematically exclude people from social cooperation. Brownlee rightly points out that while we usually adopt respectful language to describe our peers, this does not occur when we refer to people as "criminals," "irregular migrants," or "foreigners." This dehumanization is even more significant once we consider the rights that are forfeited in prisons and migration centres, a form of social deprivation that can be considered acceptable only if we do not acknowledge migrants and convicted people as human beings. These injustices, Brownlee concludes, need to be rectified if we want to ensure a society that reassures "us that we are accepted, valued, and needed" (Brownlee 2020).

Being Sure of Each Other clearly represents a fundamental contribution in moral and political philosophy by expanding the scope of human rights and developing a perspective that can shed light on and address the injustices of our societies. Brownlee persuasively challenges the standard view of sociality, clearly points out the shortcoming of the liberal framework, and develops a convincing and challenging alternative. Despite these undebatable merits, some clarifications are in order regarding what it means to be there for others, especially strangers, and what actions should be adopted by individuals to challenge systematically unjust practices. Let me briefly clarify these points.

To provide a paradigmatic example of the idea of being there for others, Brownlee starts her analysis by focusing on a dialogue between Piglet and Pooh, two characters in A. A. Milne's House at Pooh Corner. This example is very effective and clarifies what Brownlee means by authentic social interaction, but it involves two friends. Friendship clearly requires being there for others, but it also entails knowing people well, reciprocally showing your private characteristics and flaws, and being partial toward your friends (Stroud 2006). If this level of transparency and partiality is required by the perspective defended by Brownlee, her account may be even more demanding and invasive that it might appear at first glance. We might be happy to show our inner selves to our friends and to be connected with them in virtue of this intimacy, but we pretend that strangers acknowledge us as equals and are there for us even if we are reciprocally opaque. It might be claimed that Brownlee grounds her perspective in this form of opacity respect (Carter 2011). If this were the case, though, her view would entail a liberal interpretation of personal freedom that is not compatible with the perfectionistic framework she aims at promoting. In order to overcome this tension, it seems necessary to more clearly define the idea of respect that grounds this analysis and the content of authentic social relationships among strangers. 
A further element to develop concerns our duties to challenge unjust social practices. Brownlee seems to suggest that we should avoid contributing to these injustices by, for instance, adopting respectful language. Though this view is persuasive at first, a detailed analysis shows that it is not enough given the framework she develops. If we face cases of significant social deprivation and acknowledge that we have an interest in contributing to the lives of others, we should actively challenge these injustices by directly engaging in political actions. Even if this point is not explicitly made by Brownlee, it would allow us to more clearly define what it means to be there for others within contexts that systematically deny this possibility. To conclude, it is important to understand what Brownlee means by being there for others, what the implications of this approach are, and how it can be realized in a society that is far from ideal. Being Sure of Each Other is an important contribution to the contemporary debate on the content and scope of our social rights and freedoms precisely because it allows us to raise these questions and provides a framework for addressing them.

\section{References}

Brownlee K (2020) Being sure of each other. An essay on social rights and freedoms. Oxford University Press, Oxford

Carter I (2011) Respect and the basis of equality. Ethics 121(3):538-571

Stroud S (2006) Epistemic partiality in friendship. Ethics 116(3):498-524

Publisher's Note Springer Nature remains neutral with regard to jurisdictional claims in published maps and institutional affiliations. 